\title{
Providing informal care next to paid work: explaining care-giving gratification, burden and stress among older workers
}

\author{
Olga Grünwald ${ }^{1,2 *}$ (D), Marleen Damman ${ }^{1,3}$ and Kène Henkens ${ }^{1,2,4}$ \\ ${ }^{1}$ Netherlands Interdisciplinary Demographic Institute (NIDI), The Hague, The Netherlands, ${ }^{2}$ Department \\ of Health Sciences, University Medical Center Groningen, Groningen, The Netherlands, ${ }^{3}$ Department of \\ Sociology, Radboud University, Nijmegen, The Netherlands and ${ }^{4}$ Department of Sociology, University of \\ Amsterdam, Amsterdam, The Netherlands \\ ${ }^{*}$ Corresponding author. Email: grunwald@nidi.nl
}

(Accepted 29 January 2020; first published online 11 March 2020)

\begin{abstract}
With an increasing retirement age, more older adults are combining employment with informal care-giving responsibilities. However, little is known about how older workers experience care-giving activities next to their paid jobs. This study aims to fill this gap by examining how the work situation (i.e. working hours, occupational status and perceived access to human resources practices) is associated with feelings of gratification, burden and stress in care-giving. Using data from the NIDI Pension Panel Survey, we study care-giving experiences - in other words, the extent to which care-giving activities are gratifying, burdensome or stressful - of 1,651 Dutch older workers (age 60-65) who provide care at least once per week. Multivariate analyses reveal that the work situation plays an explanatory role next to socio-demographic factors and indicators of the care-giving situation. Working care-givers who feel they have access to phased retirement and organisational health support experience care-giving as relatively less burdensome and stressful. Moreover, those with access to phased retirement experience relatively higher levels of gratification in care-giving. Our findings suggest that the availability of organisational support relates to lower levels of care-giving burden and stress, and to some extent to higher levels of gratification. Organisations thus play an important role in facilitating the combination of work and care-giving obligations in a context of longer working lives.
\end{abstract}

Keywords: informal care; employment; positive and negative care-giving experiences

\section{Introduction}

In response to the increase in potential care needs due to population ageing (Colombo et al., 2011), the role of informal care-givers in maintaining the

\footnotetext{
(C) The Author(s), 2020. Published by Cambridge University Press. This is an Open Access article, distributed under the terms of the Creative Commons Attribution-NonCommercial-NoDerivatives licence (http://creativecommons.org/ licenses/by-nc-nd/4.0/), which permits non-commercial re-use, distribution, and reproduction in any medium, provided the original work is unaltered and is properly cited. The written permission of Cambridge University Press must be obtained for commercial re-use or in order to create a derivative work.
} 
wellbeing, quality of life and health of their dependent spouses, relatives and friends is increasingly emphasised (Verbeek-Oudijk et al., 2014; Broese van Groenou and de Boer, 2016). The highest proportion of informal care-givers is found among those in mid- and later life (Hank and Stuck, 2008; Josten and de Boer, 2015), and many of them are also engaged in paid work (de Boer and Keuzenkamp, 2009). Changes in retirement systems in the form of ending of early retirement schemes and increasing retirement ages (Organisation for Economic Co-operation and Development, 2015) imply that current working care-givers must continue to combine work and care-giving until much higher ages than their earlier counterparts. However, our understanding of how older workers experience care-giving is limited. In this study, we therefore address the following question:

- To what extent do older workers experience care-giving next to their paid jobs as gratifying, burdensome and stressful, and how are these care-giving experiences related to their work situation?

Research on how individuals experience their informal care-giving is dominated by studies focusing on burden, stress and strain (e.g. Kim et al., 2006; Tolkacheva et al., 2011; Gordon et al., 2012; Braithwaite, 2016; Mello et al., 2017). Some scholars have pointed at the dual nature of care-giving experiences, meaning that care-giving may not only be appraised as potentially burdensome or stressful (Kramer, 1997b), but it may also 'evoke some response of pleasure, affirmation, or joy' (Lawton et al., 1989: 62) such as feelings of gratification. Earlier studies have simultaneously considered these different types of care-giving experiences in the case of specific illnesses such as cancer (e.g. Nijboer et al., 1999), stroke (e.g. Kruithof et al., 2015) or dementia (e.g. Labra et al., 2015). Only a handful of studies have examined this dual nature of care-giving experiences in large and diverse samples of care-givers (Raschick and Ingersoll-Dayton, 2004; Lin et al., 2012; Broese van Groenou et al., 2013; Pristavec, 2019). These studies have shown that examining so-called 'positive' and 'negative' care-giving experiences separately is of importance, because they appear to capture different dimensions of care-giving experiences (Broese van Groenou et al., 2013).

Earlier studies on predictors of care-giving experiences have predominantly paid attention to characteristics of the care-giving and the care-giver (e.g. Pinquart and Sörensen, 2003; Broese van Groenou et al., 2013). Although most of these studies recognise the importance of work as a potential precursor of care-giving experiences, it often serves as a control variable measured either using a dichotomous indicator for employment status (e.g. Pristavec, 2018) or in terms of the number of working hours (e.g. Lin et al., 2012). Treating work as a single item in this way can hide important variations in care-givers' work situations (Barnett, 1998). Research on work outcomes of care-givers (e.g. Pavalko and Henderson, 2006; Gordon et al., 2012; Kim et al., 2013; Plaisier et al., 2015) has shown that multiple characteristics of the work situation, particularly different work arrangements, are linked to care-givers' work behaviours (e.g. reduced work hours, absenteeism, performance) and work evaluations (e.g. work stress, perceived ability to balance work and care). In this study, we follow the suggestion put forward by Longacre et al. 
(2017) to examine the link between care-giving experiences and various characteristics of the work situation in more detail. This approach may provide a better understanding of which aspects of the work situation are helpful to workers with care-giving responsibilities, and as such relate to lower levels of care-giving burden and stress.

This study aims to contribute to the existing literature on care-giving experiences in three ways. First, we study the effect of a broad set of work-related factors on experiences in care-giving next to more established predictors such as measures of the care-giving situation and socio-demographic characteristics (for a review, see Carretero et al., 2009). More specifically, we examine the impact of both work characteristics (i.e. working hours, occupational status) and perceived access to a set of human resources (HR) practices (i.e. flexplace, flextime, phased retirement, medical examinations) on how the care-giving is experienced by the caregiver. Second, instead of focusing on working care-givers of all ages, we specifically focus on older workers who provide informal care. It is highly relevant to study this group, given that many older workers are in a phase of life in which care demands of family members or friends are present at the same time as they are being confronted with a higher retirement age. Third, we aim to improve our understanding of the dual nature of care-giving experiences, by looking at how the work situation contributes to care-giving burden and stress - but also taking into account positive aspects of care-giving as shown in previous research in an explorative way. We thus examine simultaneously the extent to which care-giving is experienced as being gratifying, burdensome and stressful. Where prior research has examined such experiences in small-scale samples of limited scope, we study them in a large and diverse sample of Dutch individuals who carry out various care-giving tasks for family members and friends.

The Netherlands, where this study is situated, represents an interesting case for studying how older workers experience care-giving next to their paid job. Recent policies stimulated communities and families to contribute to a greater extent to the care of people with moderate needs, thereby limiting the institutionalisation of dependent people (Verbeek-Oudijk et al., 2014). Besides that, early exit routes into retirement were blocked and the state pension age for cohorts born after 1950 is being increased from 65 to 67 years and will thereafter be linked to the life expectancy (van Solinge and Henkens, 2017). These policy changes are also reflected in the Dutch labour market participation figures. Whereas in 2003 the net labour market participation in the age group 60-65 years was 22 per cent, this has increased to 58 per cent in 2018 (Statistics Netherlands, 2019). Today's older workers thus have to work until much older ages than their earlier counterparts. Many of them worry about their ability to do so (van Solinge and Henkens, 2017).

\section{Theoretical background}

Care-giving experiences are the subjective response to care-giving, or the 'cognitive and affective responses to the demands of caregiving and one's own behaviour in relation to those demands' (Lawton et al., 1991: 181). On the one hand, individuals assess the extent to which the care-giving demands affect them on an intra-personal 
level (Broese van Groenou et al., 2013). This is often expressed in feelings of reward, satisfaction, uplift or gratification (Kramer, 1997b; Zarit, 2012). On the other hand, they evaluate how care-giving demands are met and infringe upon other life domains. If care-givers have difficulties in meeting care-giving demands, adverse feelings towards care-giving may arise, such as experiencing care-giving as burdensome or stressful. These two types of evaluations have often been framed as 'positive' and 'negative' experiences in care-giving (Lin et al., 2012; Broese van Groenou et al., 2013), but were shown not to represent opposites on the same dimension as those terms may suggest. Rather positive and negative experiences in care-giving reflect different dimensions - they can occur simultaneously and differ in terms of predictors (Broese van Groenou et al., 2013).

Whether care-givers are able to draw positive experiences from care-giving is related to their motivations for care-giving (Farran, 1997; Kramer, 1997a; Broese van Groenou et al., 2013). When people provide care because they like to help others, and hold a belief that providing care is a good thing in itself, rather than an obligation, the experience is more likely to be gratifying (Broese van Groenou et al., 2013). Non-kin care-givers have been found to be less likely to provide care out of obligation and have higher levels of intrinsic motivation (Lyonette and Yardley, 2003). Research has also found that religion fosters a belief system that incorporates a desire to help others (e.g. Farran, 1997). From this line of reasoning, it can be expected that providing care to non-kin and higher levels of religiosity are linked to greater feelings of care-giving gratification.

To study negative care-giving experiences, the stress-process model (Pearlin et al., 1990) and its modifications (e.g. Yates et al., 1999; Verbakel et al., 2016) have often been used. One major commonality between these models is that they propose that intense care-giving situations are likely to be stressors for care-givers because they may 'threaten them, thwart their efforts, fatigue them, and defeat their dreams' (Pearlin et al., 1990: 586) - which may result in care-giving burden and stress. Moreover, the extent to which care-givers experience care-giving as burdensome or stressful has been proposed to differ by the background characteristics of the care-giver - these characteristics define the social and personal resources available to meet the challenges of care-giving (Pearlin et al., 1990). Taken together, both characteristics of the care situation and the care-giver are generally expected to affect care-giving burden and stress.

The work context represents another potential stressor as working care-givers may experience 'cross-pressures and dilemmas at the junctures of care-giving and occupation' (Pearlin et al., 1990: 588). Even though the importance of work for understanding care-giving experiences is acknowledged in stress-process-based models (i.e. by focusing on care-givers' appraisal of how well they can combine work and care-giving), it remains unclear in which work situations working caregivers can be expected to experience higher or lower levels of care-giving burden and stress. Focusing on structural work predictors allows identification of modifiable work conditions that may protect older employed care-givers from feelings of care-giving burden and stress.

In this study, we add structural work predictors to existing theoretical models as additional factors for explaining feelings of burden and stress in care-giving. We propose that demands and resources produced by the work situation may aggravate 
(or ease) the combination of work and care, and in turn, may relate to higher (or lower) levels of care-giving burden and stress. To a certain extent this might also hold true for levels of care-giving gratification, but we pay attention to this in an explorative way, given that earlier studies highlighted another type of central predictors of gratification. Overall, we focus on three different types of structural work conditions that may indicate demands (levels of work involvement) and resources (access to workplace flexibility and workplace health support) at work. We elaborate on these factors in the following sections.

\section{Work involvement}

Difficulties in combining work and care-giving may arise because care-givers need to divide their personal resources such as time, physical energy and psychological energy between work and care (Voydanoff, 2004). The extent to which people invest personal resources in a life domain depends on how important this role is to their self-concept (Carlson and Frone, 2003). The more involved individuals are in a role, the more difficult they find it to take resources out of that role and invest them in another role. Carlson and Frone (2003) distinguish between behavioural and psychological role involvement. In essence, the more time spent by individuals on one activity, the higher their behavioural involvement with that activity. This finding is supported by research on work attachment, which shows that fulltime employees are more attached to their work than part-time employees (Lilly et al., 2007). Psychological involvement refers to how much mental and cognitive effort workers invest in their work. Research has shown that higher-status workers are more psychologically involved in their work than lower-status workers (e.g. Schieman et al., 2006). If a greater involvement in work makes it more difficult to direct resources towards other activities (Carlson and Frone, 2003) such as caregiving (Gordon and Rouse, 2013), care-giving may be experienced as relatively more burdensome and stressful for workers with high levels of work involvement. Therefore, we propose the work involvement hypothesis, which predicts that higher levels of work involvement as indicated by full-time employment and higher occupational status are associated with higher levels of care-giving burden and stress.

\section{Workplace flexibility}

Workplace flexibility, which is 'the ability of workers to make choices influencing when, where, and for how long they engage in work-related tasks' (Hill et al., 2008: 152), is highly valued by older workers (Damman and Henkens, 2018), and has often been proposed to ease the combination of work and care-giving (e.g. Brown and Pitt-Catsouphes, 2016). Through workplace flexibility, working care-givers gain control and autonomy over their personal resources. Having control and autonomy at work may ease the allocation of time and energy according to the needs of care receivers. Flextime allows working care-givers to decide when to start or stop working, allowing them to arrange their work schedule in a way that is informed by the needs of the care receiver. Flexplace allows working care-givers to decide where to work and to be closer to the care receiver if needed. Phased retirement, another form of workplace flexibility, allows people to determine how much 
work to do by reducing the number of working hours prior to retirement, and working care-givers thus have more time to engage in care-giving. Given that caregiving is often unpredictable, the perception of access to workplace flexibility may in itself alleviate burden and stress. We therefore propose the workplace flexibility hypothesis, which predicts that older working care-givers who perceive that they can access flexplace, flextime and phased retirement experience lower levels of caregiving burden and stress than those who do not.

\section{Workplace health support}

Care-givers engage in health-promoting and health-preventive behaviour less often than non-care-givers (e.g. Hoffman et al., 2012). Chaix et al. (2006) propose that care-givers may be less inclined to invest in their own health because they may perceive such an investment to be unwarranted in light of the more severe health needs of the care receiver; alternatively, they may not have the energy to care for their own health. Working care-givers may be particularly at risk of not engaging in healthpromoting behaviours, given that both activities may deplete resources. Arksey (2002) shows that one major concern of working care-givers is their own health. However, if the organisation provides health support by offering regular medical examinations, these people may have to worry less about their current and future health status because they have sufficient access to health support. Perceptions of organisational health support may thus provide a sense of security that the organisation is also concerned with the health of its employees. This may in turn indicate a supportive work environment, which has been found to ease the combination of work and care-giving (e.g. Gordon et al., 2012). Along these lines, we propose the workplace health support hypothesis, which predicts that perceived access to workplace medical support is associated with lower levels of care-giving burden and stress.

\section{Design and methods \\ Sample}

In this study, we draw on data obtained from the first wave of the NIDI Pension Panel Study (NPPS) collected in 2015 (Henkens et al., 2017). This is a prospective cohort study sampled via three of the largest pension funds in the Netherlands that cover different sectors (government, education, construction, care, social work). These pension funds represent around 49 per cent of all Dutch wage-employed workers. In the NPPS, a stratified sample of organisations $(\mathrm{N}=2,750)$ based on organisational size and sector was drawn. Around 1,500 small organisations (10-49 employees), 1,000 medium organisations (50-249 employees) and 250 large organisations (more than 250 employees) were selected. Within these organisations, a random sample of older workers aged 60-65 who work at least 12 hours a week $(\mathrm{N}=15,480)$ was drawn. These workers received a mail questionnaire from their pension fund, but were also able to fill in an online version. In total, 6,793 questionnaires from 1,669 organisations were returned after two reminders, equivalent to a response rate of 44 per cent for participants and 43 per cent for organisations. For the analyses, our base sample consists of older workers who provide care at least 
once a week. After excluding respondents for whom information on the dependent variables was missing, our analytical sample consisted of 1,651 older working caregivers from 680 organisations (on average 2.4 employees per organisation). These numbers show that about one out of four older workers included in the NPPS provides informal care at least once per week.

\section{Measures}

To measure the dual nature of care-giving experiences, we focus on three types of feelings older workers may receive from care-giving activities: gratification, burden and stress. In the NPPS, respondents are requested to take all their informal care-giving activities into consideration when being asked about their care-giving experiences. The specific question asked in the questionnaire was: 'To what extent is providing informal care ...satisfactory/gratifying, ...burdensome, and ...stressful'. The response categories for each of the three outcomes are $1=$ not at all, $2=$ a little, $3=$ fairly and $4=$ very.

The main predictor variables are characteristics of the work situation, i.e. working hours, occupational status and the perceived access to a series of HR practices (flexplace, flextime, phased retirement and regular medical examinations). In addition, we control for well-established correlates of experiences in care-giving, namely the care-giving situation (relationship to the care receiver, physical care, daily care-giving, long-term care-giving) and the care-giver's socio-demographic characteristics (age, gender, marital status, children, health, wealth, religion). We also take organisational size and sector into account. Table 1 presents the mean, standard deviation, coding and wording of survey questions for all dependent and independent variables used in the analyses. In general, item non-response was lower than 6 per cent (found in the wealth variable), and was dealt with using single stochastic regression imputation (Enders, 2010).

\section{Analyses}

To investigate how care-giving gratification, burden and stress are related to the work situation of older workers, we ran three separate multi-level ordinal logistic regression models. On the individual level, we include characteristics of the work situation, measures of the care situation and indicators of the care-giver's sociodemographic characteristics. On the organisational level, we control for the size and sector of the organisation. The intra-class correlation (ICC) indicates that 1 per cent of the variation in gratification is located at the organisational level. The ICC is slightly higher for burden (ICC $=3 \%$ ) and stress (ICC $=5 \%$ ).

\section{Results}

To answer the first part of our research question, namely to what extent do older workers experience care-giving next to their paid jobs as gratifying, burdensome and stressful, we start with presenting our descriptive findings (see Table 1). To study the second part of the research question, focusing on how care-giving experiences are related to the work situation, we estimated multivariate multi-level models. 
Table 1. Means, standard deviations, coding of independent variables and wording of survey questions

\begin{tabular}{|c|c|c|c|c|}
\hline Variables & Mean & SD & Coding and psychometric properties & Description/wording (questions translated from Dutch) \\
\hline \multicolumn{5}{|l|}{ Care-giving experience: } \\
\hline Gratification & 2.12 & 0.87 & \multirow{3}{*}{$\begin{array}{l}\text { Ordinal variable, range } 1 \text { (not at all) to } 4 \text { (very), } \\
\text { respectively }\end{array}$} & \multirow{3}{*}{$\begin{array}{l}\text { Question: To what extent is providing informal care ... } \\
\text { satisfactory/gratifying, ....burdensome, and ....stressful }\end{array}$} \\
\hline Burden & 3.11 & 0.93 & & \\
\hline Stress & 3.39 & 0.85 & & \\
\hline \multicolumn{5}{|c|}{ Socio-demographic characteristics: } \\
\hline Age & 61.98 & 1.60 & Continuous variable, range $60-65$ years & Question: In what year were you born? \\
\hline Gender & 0.47 & & Dummy variable coded $0-1,1=$ woman & Question: Are you a man or a woman? \\
\hline Partnered & 0.83 & & $\begin{array}{l}\text { Dummy variable coded } 0-1,1=\text { with partner } \\
\text { (married, co-habitation, living apart) }\end{array}$ & $\begin{array}{l}\text { Question: Do you have a partner? Response categories } \\
\text { are } 1=\text { yes, I am married; } 2=\text { yes, I co-habit with a } \\
\text { partner; } 3=\text { yes, I do have a partner but we do not live } \\
\text { together; } 4=\text { no, I am single }\end{array}$ \\
\hline Number of children & 2.11 & 1.20 & Continuous variable, range $0-6$ & $\begin{array}{l}\text { Question: Do you have children? If so, how many? } \\
\text { (cut-off point: six children) }\end{array}$ \\
\hline Health status & 3.14 & 0.85 & One-item scale, range 1 (very poor) to 5 (excellent) & $\begin{array}{l}\text { Question: How would you characterise your health in } \\
\text { general? Response categories are } 1=\text { excellent to } \\
5=\text { very poor and were reverse-coded }\end{array}$ \\
\hline Wealth & 120.58 & 188.03 & Quasi-interval measure, range $2.5-750$ & $\begin{array}{l}\text { Question: How large do you estimate your total wealth } \\
\text { (own house, savings, stocks, etc. minus debts/ } \\
\text { mortgage) to be? Response categories are } 1=\text { less than } \\
€ 5,000 \text { to } 7=\text { more than } € 500,000 \text {. We used class } \\
\text { averages and report values in thousands }\end{array}$ \\
\hline Religion & 2.62 & 1.26 & $\begin{array}{l}\text { One-item scale, range } 1 \text { (very unimportant) to } 5 \\
\text { (very important) }\end{array}$ & $\begin{array}{l}\text { Question: Can you indicate for the following things how } \\
\text { important they are in your life?: My religion/faith. } \\
\text { Response categories are } 1=\text { very important to } 5=\text { very } \\
\text { unimportant and were reverse-coded }\end{array}$ \\
\hline
\end{tabular}




\begin{tabular}{|c|c|c|c|c|}
\hline Variables & Mean & SD & Coding and psychometric properties & Description/wording (questions translated from Dutch) \\
\hline \multicolumn{5}{|l|}{ Care-giving situation: } \\
\hline Care to partner & 0.41 & & \multirow{5}{*}{$\begin{array}{l}\text { Dummy variable coded } 0-1,1=\text { provision of care to } \\
\text { respective person }\end{array}$} & \multirow{6}{*}{$\begin{array}{l}\text { Question: Do you provide help to family members or } \\
\text { friends who are ill or in need of help? If yes, what kind } \\
\text { of help? Provision of care to (a) partner, (b) child, (c) } \\
\text { parent/in-law, (d) brother/sister, (e) friend or } \\
\text { acquaintance, (f) neighbours. Type of help given: (1) } \\
\text { domestic help, (2) physical care, (3) accompaniment } \\
\text { and transportation, (4) administration }\end{array}$} \\
\hline Care to child & 0.32 & & & \\
\hline Care to parent(-in law) & 0.58 & & & \\
\hline Care to sibling & 0.18 & & & \\
\hline Care to friend/neighbour & 0.26 & & & \\
\hline Physical care & 0.29 & & $\begin{array}{l}\text { Dummy variable coded } 0-1,1=\text { provision of } \\
\text { physical care to any person }\end{array}$ & \\
\hline Daily care-giving & 0.17 & & Dummy variable coded $0-1,1=$ Daily & $\begin{array}{l}\text { Question: How frequently do you provide that help? } \\
\text { (1=daily; } 2 \text { = several times a week; } 3 \text { = about weekly) }\end{array}$ \\
\hline Long-term care & 0.26 & & $\begin{array}{l}\text { Dummy variable coded } 0-1,1=\text { care-giver at age } \\
50-59\end{array}$ & $\begin{array}{l}\text { Question: Could you indicate whether and when you } \\
\text { experienced the following events during your career? } \\
\text { Provided long-term care at age 50-59 }\end{array}$ \\
\hline \multicolumn{5}{|l|}{ Work situation: } \\
\hline Full-time work & 0.47 & & Dummy variable coded $0-1,1=36-50$ hours & $\begin{array}{l}\text { Question: How many hours do you work on average } \\
\text { (per week)? Excluding overtime (cut-off point: } 50 \text { hours) }\end{array}$ \\
\hline Occupational status & 0.04 & 0.90 & $\begin{array}{l}\text { Coding is based on } 2008 \text { International } \\
\text { Socio-economic Index of Occupational Status } \\
\text { (Ganzeboom and Treiman, 1996) and was } \\
\text { standardised using the full sample }\end{array}$ & $\begin{array}{l}\text { Question: What is your job or profession? In which } \\
\text { category could your job or profession be grouped? } \\
\text { Response categories are } 1=\text { higher intellectual or } \\
\text { free profession; } 2 \text { = higher executive profession; } \\
3=\text { intermediate intellectual or free profession; } \\
4=\text { intermediate executive or commercial profession; } \\
5=\text { other non-manual work; } 6 \text { = skilled and executive } \\
\text { manual work; } 7 \text { = semi-skilled manual work; } \\
8=\text { unskilled and experienced manual work; } \\
9=\text { agricultural profession; } 10=\text { I don't know }\end{array}$ \\
\hline
\end{tabular}




\section{Perceived access to HR practices:}

\begin{tabular}{|c|c|c|c|}
\hline Flexplace & 0.46 & $\begin{array}{l}\text { Dummy variable coded } 0-1,1=\text { making use or } \\
\text { having the possibility to make use of HR practice, } \\
\text { respectively }\end{array}$ & \multirow{4}{*}{$\begin{array}{l}\text { Question: Are the following measures available in your } \\
\text { organisation/company? (a) working from home, (b) } \\
\text { flexible working hours, (c) reduction of work hours } \\
\text { prior to retirement, (d) regular medical examinations. } \\
\text { Response categories are } 1=\text { yes, I make use of it; } 2=\text { no, } \\
\text { but it is possible to use it; } \\
3=\text { no, not possible }\end{array}$} \\
\hline Flextime & 0.50 & $\begin{array}{l}\text { Dummy variable coded } 0-1,1=\text { making use or } \\
\text { having the possibility to make use of HR practice, } \\
\text { respectively }\end{array}$ & \\
\hline Phased retirement & 0.74 & $\begin{array}{l}\text { Dummy variable coded } 0-1,1=\text { making use or } \\
\text { having the possibility to make use of HR practice, } \\
\text { respectively }\end{array}$ & \\
\hline Medical examinations & 0.45 & $\begin{array}{l}\text { Dummy variable coded } 0-1,1=\text { making use or } \\
\text { having the possibility to make use of HR practice, } \\
\text { respectively }\end{array}$ & \\
\hline \multicolumn{4}{|c|}{ Organisational characteristics: } \\
\hline \multicolumn{4}{|l|}{ Size: } \\
\hline Small & 0.27 & \multirow{3}{*}{$\begin{array}{l}\text { Categorical variable on Level } 2 \text {. Small }(<50 \\
\text { employees); medium ( } 50-250 \text { employees); large } \\
\text { ( }>250 \text { employees) }\end{array}$} & \multirow{3}{*}{$\begin{array}{l}\text { Question: Approximately how many people work in } \\
\text { your work establishment? }\end{array}$} \\
\hline Medium & 0.55 & & \\
\hline Large & 0.18 & & \\
\hline \multicolumn{4}{|l|}{ Sector: } \\
\hline Government & 0.25 & \multirow[t]{5}{*}{ Categorical variable on Level 2} & \multirow{5}{*}{$\begin{array}{l}\text { Information about sector is obtained via the three } \\
\text { participating pension funds }\end{array}$} \\
\hline Education & 0.25 & & \\
\hline Construction & 0.18 & & \\
\hline Care & 0.14 & & \\
\hline Social work & 0.18 & & \\
\hline
\end{tabular}

Notes: The descriptive statistics are based on the values prior to imputation. SD: standard deviation. HR: human resources. 


\section{Descriptive findings}

Overall, 70 per cent of working care-givers report that they feel fairly/very gratified with their care-giving activities. Also, a substantial proportion experience them as fairly/very burdensome (26\%) and stressful (16\%). There is a clear gender difference in care-giving burden and stress. The share of women who experience caregiving as fairly/very burdensome (34\%) and stressful (22\%) is substantially higher than among men (19\% and 11\%, respectively). Equal shares of men and women experience care-giving as gratifying. The correlation of the three variables (Spearman's rho) points to the fact that feelings of gratification are different from feelings of burden and stress. While the correlation between burden and stress is relatively high ( $r h o=0.65, p<0.01)$, the correlations between gratification and burden (rho $=-0.08, p<0.01)$ and gratification and stress $($ rho $=-0.23, p<0.01)$ are much lower.

\section{Multivariate findings}

Table 2 presents the results of the multi-level ordinal logistic regression models for experiencing care-giving as gratifying, burdensome and stressful. We hypothesise that work involvement, a lack of workplace flexibility and limited organisational health support relate to higher levels of care-giving burden and stress. While we do not find support for the work involvement hypothesis, our findings are in line with the other two hypotheses. We find partial support for the workplace flexibility hypothesis. Older workers who perceive that they have access to phased retirement experience relatively lower levels of care-giving burden and stress. We find no significant differences in care-giving experiences between older workers who perceive having access to flexplace or flextime practices and those who do not have it. The results also support the workplace health support hypothesis. Perceived access to regular medical examinations is significantly linked to lower levels of care-giving burden and stress.

To illustrate the relationship between work situation and these experiences in care-giving, we calculated cumulative predicted probabilities for the effects of access to phased retirement and medical examinations on care-giving burden (Figure 1) and stress (Figure 2) while keeping all other variables constant (care-giving situation and care-giver's characteristics). The probability of experiencing care-giving as very or fairly burdensome is substantially lower when there is access to phased retirement (24\% versus $30 \%$ when there is no access; see Figure 1, left panel). The probability of high levels of care-giving burden is substantially lower (23\%) when there is access to medical examinations than in the case of no access $(29 \%$, see Figure 1, right panel). Figure 2 portrays a similar picture for care-giving stress.

Next to characteristics of the work situation, characteristics of the care-giving situation and care-giver are significantly linked to care-giving burden and stress, as could be expected based on the stress-process model. More intense care-giving situations, as indicated by providing physical care, daily care and long-term care are associated with greater levels of care-giving burden and stress. Also, providing care to a parent is significantly linked to greater levels of burden and stress. With regard to differences in burden and stress by background characteristics of the care- 
Table 2. Multi-level ordinal logit models of explaining gratifying, burdensome and stressful care-giving experiences

\begin{tabular}{|c|c|c|c|c|c|c|c|c|c|}
\hline & \multicolumn{3}{|c|}{ Gratifying } & \multicolumn{3}{|c|}{ Burdensome } & \multicolumn{3}{|c|}{ Stressful } \\
\hline & Coef. & & SE & Coef. & & SE & Coef. & & SE \\
\hline \multicolumn{10}{|c|}{ Socio-demographic characteristics: } \\
\hline Age & -0.02 & & 0.03 & 0.01 & & 0.03 & -0.01 & & 0.03 \\
\hline Female & -0.15 & & 0.13 & 0.24 & & 0.13 & 0.39 & $\star *$ & 0.14 \\
\hline Partnered & -0.20 & & 0.14 & -0.06 & & 0.14 & 0.03 & & 0.15 \\
\hline Children & -0.01 & & 0.04 & -0.08 & & 0.04 & -0.07 & & 0.05 \\
\hline Health & 0.19 & $\star \star$ & 0.06 & -0.24 & $\star \star \star$ & 0.06 & -0.31 & $\star \star \star$ & 0.07 \\
\hline Wealth & 0.00 & & 0.00 & 0.00 & & 0.00 & 0.00 & & 0.00 \\
\hline Religion & 0.15 & $\star \star \star$ & 0.04 & 0.00 & & 0.04 & -0.05 & & 0.04 \\
\hline \multicolumn{10}{|l|}{ Care-giving situation: } \\
\hline Care to partner & -0.11 & & 0.12 & -0.27 & * & 0.12 & -0.12 & & 0.13 \\
\hline Care to child & 0.09 & & 0.11 & 0.31 & $\star \star$ & 0.11 & 0.27 & * & 0.12 \\
\hline Care to parent(in-law) & -0.16 & & 0.10 & 0.40 & $\star * *$ & 0.11 & 0.54 & $\star \star \star *$ & 0.12 \\
\hline Care to sibling & 0.10 & & 0.12 & 0.16 & & 0.13 & 0.14 & & 0.14 \\
\hline Care to friends/neighbours & 0.46 & 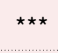 & 0.11 & 0.20 & & 0.12 & -0.17 & & 0.13 \\
\hline Physical care & 0.07 & & 0.11 & 0.62 & $\star \star \star$ & 0.11 & 0.47 & $\star \star \star$ & 0.12 \\
\hline Daily care-giving & 0.33 & * & 0.14 & 0.91 & $\star \star \star$ & 0.14 & 0.72 & $\star \star \star$ & 0.15 \\
\hline Long-term care-giver & -0.38 & $\star \star \star \star$ & 0.11 & 1.02 & $\star \star \star$ & 0.12 & 0.97 & $\star \star \star$ & 0.12 \\
\hline
\end{tabular}


Table 2. (Continued.)

\begin{tabular}{|c|c|c|c|c|c|c|c|c|c|}
\hline & \multicolumn{3}{|c|}{ Gratifying } & \multicolumn{3}{|c|}{ Burdensome } & \multicolumn{3}{|c|}{ Stressful } \\
\hline & Coef. & & SE & Coef. & & SE & Coef. & & SE \\
\hline \multicolumn{10}{|l|}{ Work situation: } \\
\hline Full-time work & -0.05 & & 0.12 & -0.06 & & 0.12 & 0.08 & & 0.13 \\
\hline Occupational status & -0.02 & & 0.07 & 0.09 & & 0.07 & 0.11 & & 0.08 \\
\hline \multicolumn{10}{|l|}{ Human resources practice: } \\
\hline Flexplace & -0.16 & & 0.12 & -0.05 & & 0.13 & 0.04 & & 0.14 \\
\hline Flextime & 0.08 & & 0.12 & 0.11 & & 0.12 & 0.04 & & 0.13 \\
\hline Phased retirement & 0.28 & $\star \star *$ & 0.11 & -0.32 & ** & 0.11 & -0.27 & * & 0.12 \\
\hline Medical examinations & 0.06 & & 0.11 & -0.34 & ** & 0.12 & -0.37 & ** & 0.13 \\
\hline \multicolumn{10}{|c|}{ Organisational characteristics: } \\
\hline \multicolumn{10}{|l|}{ Sector (Ref. Care): } \\
\hline Government & -0.35 & * & 0.17 & 0.15 & & 0.19 & 0.29 & & 0.19 \\
\hline Education & -0.38 & * & 0.18 & 0.11 & & 0.20 & 0.21 & & 0.21 \\
\hline Construction & -0.52 & * & 0.21 & 0.22 & & 0.23 & -0.06 & & 0.25 \\
\hline Social work & -0.17 & & 0.17 & 0.19 & & 0.19 & 0.20 & & 0.19 \\
\hline \multicolumn{10}{|l|}{ Size (Ref. Large): } \\
\hline Small & 0.03 & & 0.16 & -0.06 & & 0.18 & 0.15 & & 0.19 \\
\hline Medium & 0.05 & & 0.13 & -0.17 & & 0.15 & 0.08 & & 0.16 \\
\hline Var(organisation) & 0.00 & & 0.06 & 0.12 & & 0.08 & 0.06 & & 0.08 \\
\hline
\end{tabular}




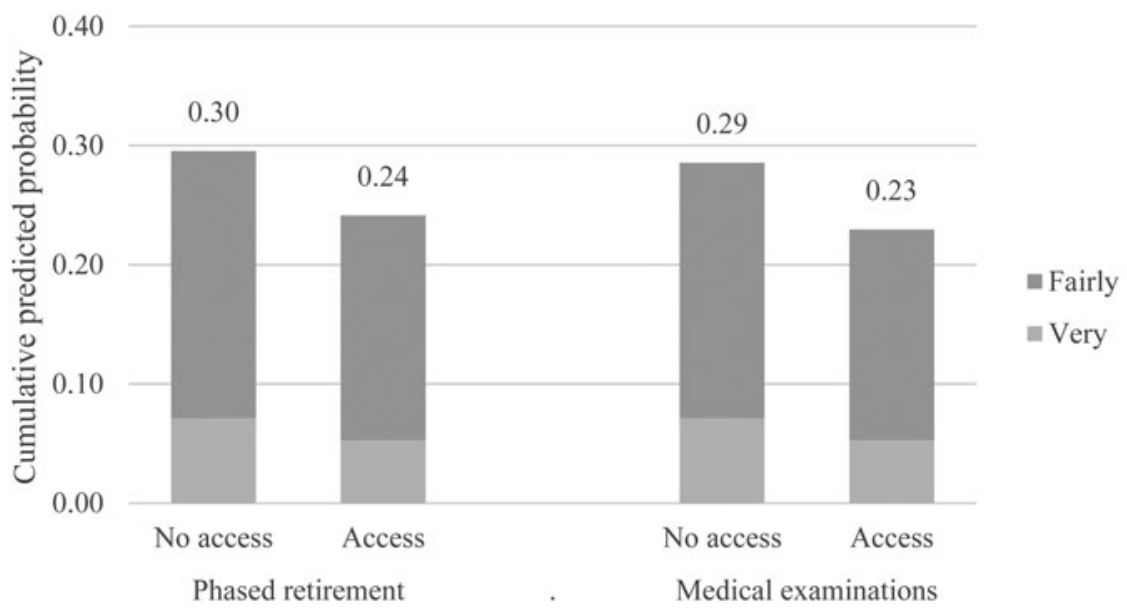

Figure 1. Cumulative predicted probabilities of care-giving burden.

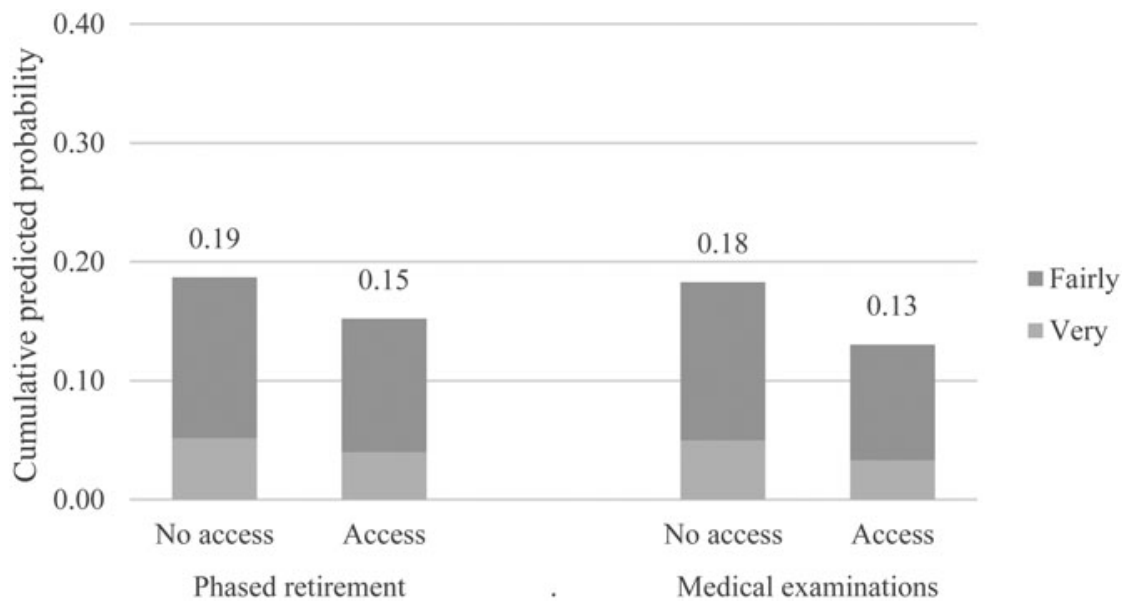

Figure 2. Cumulative predicted probabilities of care-giving stress.

giver, we find that a lower health status is significantly linked to higher levels of burden and stress. Interestingly, the gender difference in levels of stress remains significant also when taking the work context, care-giving situation and other sociodemographic characteristics into account. Additional analyses were run to test whether the effects of the work situation on care-giving burden and stress differ by gender, but none of these interaction terms were significant.

When turning to the results for care-giving gratification, we find that perceived access to phased retirement is significantly associated with higher levels of caregiving gratification. We also find that care-givers doing paid work in the care sector experience greater levels of care-giving gratification than their counterparts in other sectors (except for social work). Furthermore, consistent with our expectations, we 
find that religiosity and providing care to friends or neighbours are significantly linked to care-giving gratification. Also, providing daily care is significantly linked to greater levels of care-giving gratification.

\section{Discussion}

Providing care to family members and friends is a common area of activity among older workers. This study examined to what extent older workers who provide informal care at least once per week experience their care-giving activities as being gratifying, burdensome and stressful, and studied how those care-giving experiences are related to their work situation. One prominent assumption is that combining care-giving with paid work may be difficult (e.g. Tolkacheva et al., 2011). Our results provide evidence that care-giving is a gratifying experience for a majority of Dutch older workers. More than two-thirds of older working care-givers experience their care-giving activities as gratifying, while one in three working care-givers get limited gratification from care-giving. At the same time, care-giving also evokes feelings of burden and stress. Around one in five older working care-givers experience care-giving as fairly or very burdensome and stressful.

For understanding in which situations working care-givers experience feelings of burden and stress in care-giving, our findings highlight structural aspects of the work situation as important predictors next to the more commonly studied care-giving situation and the socio-demographic characteristics of care-givers (e.g. Pinquart and Sörensen, 2003; Broese van Groenou et al., 2013). This suggests that the work situation of working care-givers is not only linked to their work outcomes (e.g. Plaisier et al., 2015), but also to their care-giving outcomes. Taking a closer look at the structural work situation of working care-givers - thereby moving beyond the subjective appraisal of the work-care combination as has been central in stress-process-based theoretical models - allows us to identify those work factors that may protect working care-givers from feelings of burden and stress in care-giving.

We find that perceived access to phased retirement is linked with lower levels of care-giving burden and stress. This finding implies that perceived control over the number of working hours, and therefore to a certain extent control over workload, may be helpful for reducing care-giving burden and stress. However, we do not find that perceived access to flexplace and flextime are significantly associated with lower levels of care-giving burden and stress among older working care-givers. Control over when and where to work seems thus not to reduce care-giving burden and stress. This seems to suggest that working care-givers who can work from home or make use of flexible working time still experience care-giving as stressful and burdensome - this may reflect the fact that they still need to be available for work and care-giving. This is particularly interesting, given that flexplace and flextime have often been proposed as ways in which organisations can support workers with care-giving responsibilities (e.g. Brown and Pitt-Catsouphes, 2016). Our findings illustrate that working care-givers at the end of their careers may rather seek to reduce their work obligations in order to gain more time and energy - either for care-giving or to gain respite from it.

Our findings also show that perceived access to medical support is significantly associated with lower levels of care-giving burden and stress. This finding 
underscores the fact that the health concerns of working care-givers may pose an additional stressor and have a knock-on effect in terms of care-giving burden and stress. Given the demands of both work and care-giving, working care-givers may lack sufficient time and energy to engage in health-promoting and healthpreventive behaviours next to their work and care-giving responsibilities. Regular medical examinations at work would then seem to provide a way for working caregivers to support their own health without investing additional personal resources. Because the perception of access to medical examinations is linked to lower caregiving burden and stress, organisational health support would seem to represent a form of supportive work environment for working care-givers. This is particularly interesting given that workers in the Netherlands, as well as in other European countries, have access to formal medical care (European Union, 2010) - the perception of access to medical examinations at work seems to nevertheless represent an additional form of health support that relates to lower levels of burden and stress of care-giving.

At a first glance, the difference in levels of care-giving burden and stress between those with and without access to HR practices might seem relatively small ( $c f$. Figures 1 and 2). Nevertheless, it should be kept in mind that only aspects of the work situation, which are rather distant from care-giving experiences, are changed while keeping the care situation constant. Against this background, the difference in care-giving experiences between working care-givers with and without access to phased retirement and medical examinations can be considered as meaningful. Together our findings suggest that the availability of organisational support from employers relates to lower levels of burden and stress. Although this finding seems to hold for male and female working care-givers, more attention may still be needed for the care-giving stress experienced by older working women. The women included in this study experienced substantially higher levels of stress than men, which could not be attributed to differences in their work, care-giving or socio-demographic situation. Achieving a better understanding of these gender differences is of eminent importance for ensuring that both older employed men and women can fruitfully combine care-giving with paid employment until older ages.

This study also highlights the relevance of examining gratifying as well as burdensome and stressful care-giving experiences separately. Our results show that the antecedents of gratifying experiences in care-giving are different from those that are burdensome and stressful. In fact, some of the predictors even point in the opposite direction, suggesting that the same care-giving situation can evoke different sorts of feelings in care-giving. Working care-givers who provide daily care experience greater feelings of gratification but also greater levels of burden and stress. This may suggest that these individuals are self-selecting into more intense forms of care-giving because of a motivation to care for others. In support of this view, we also find that care-givers doing paid work in the care sector experience relatively high levels of care-giving gratification, and this is also the case for more religious older workers as well as for those providing care for friends or neighbours. Both employment sector and religiosity are unrelated to levels of care-giving burden and stress. Our findings thus support the notion that positive and negative caregiving experiences are distinct from one another, rather than being opposites within the same dimension. 
In interpreting these findings, some limitations should be borne in mind. First, our dependent variables, namely care-giving gratification, burden and stress, are measured using single indicators. This may have limited our ability to capture the full range of positive and negative care-giving experiences. Second, we use a cross-sectional sample that prevents us from testing the effect of the use of HR practices on care-giving experiences. The use of longitudinal data could allow conclusions to be drawn about whether the actual use of HR practices reduces caregiving burden and stress, and should be the focus of future work. Third, this study takes place in the Netherlands, which may limit the generalisability of the findings to other countries with different welfare regimes.

In general terms, because older workers are expected to work longer but also to care more for dependent family members and friends, questions arise regarding how they experience care-giving next to their paid job. Our findings clearly show that care-giving could be a gratifying as well as a burdensome and stressful experience for working care-givers, and that their work situation is important for explaining care-giving burden and stress. In light of the closure of early retirement routes and higher retirement ages, older workers' agency over their retirement timing has become more restricted. Offering access to phased retirement would appear to ensure that working care-givers retain the autonomy to decide when and how to withdraw from the labour market, which could in turn alleviate care-giving burden and stress. Specifically, in times of extended careers and given the ever-increasing numbers of dependent people, organisations can be seen as important actors in shaping the workplace in such a way that future cohorts of informal, working caregivers can successfully combine care-giving with paid work.

Financial support. This work was supported by The Netherlands Organisation for Scientific Research (KH, VICI grant number 453-14-001; MD, VENI grant number 451-17-005) and Netspar.

\section{References}

Arksey H (2002) Combining informal care and work. Supporting carers in the workplace. Health and Social Care in the Community 10, 151-161.

Barnett RC (1998) Toward a review and reconceptualization of the work/family literature. Genetic, Social, and General Psychology Monographs 124, 125-160.

Braithwaite V (2016) Understanding stress in informal caregiving. Research on Aging 18, 139-174.

Broese van Groenou M and de Boer AH (2016) Providing informal care in a changing society. European Journal of Ageing 13, 271-279.

Broese van Groenou M, de Boer AH and Iedema J (2013) Positive and negative evaluation of caregiving among three different types of informal care relationships. European Journal of Ageing 10, 301-311.

Brown M and Pitt-Catsouphes M (2016) A mediational model of workplace flexibility, work-family conflict, and perceived stress among caregivers of older adults. Community, Work \& Family 19, 379-395.

Carlson DS and Frone MR (2003) Relation of behavioral and psychological involvement to a new fourfactor conceptualization of work-family interference. Journal of Business and Psychology 17, 515-535.

Carretero S, Garces J, Rodenas F and Sanjose V (2009) The informal caregiver's burden of dependent people. Theory and empirical review. Archives of Gerontology and Geriatrics 49, 74-79.

Chaix B, Navaie-Waliser M, Viboud C, Parizot I and Chauvin P (2006) Lower utilization of primary, specialty and preventive care services by individuals residing with persons in poor health. European Journal of Public Health 16, 209-216.

Colombo F, Llena-Nozal A, Mercier J and Tjadens F (2011) Help Wanted? Providing and Paying for Long-term Care. Paris: OECD Publishing. 
Damman M and Henkens K (2018) Gender differences in perceived workplace flexibility among older workers in the Netherlands. A brief report. Journal of Applied Gerontology. doi: 10.1177/ 0733464818800651.

de Boer AH and Keuzenkamp S (2009) Vrouwen, mannen en mantelzorg [Women, Men, and Informal Caregiving]. The Hague: Sociaal en Cultureel Planbureau.

Enders CK (2010) Applied Missing Data Analysis. New York, NY: Guilford.

European Union (2010) Charter of Fundamental Rights of the European Union (2010/C 83/02). Brussels: European Union.

Farran CJ (1997) Theoretical perspectives concerning positive aspects of caring for elderly persons with dementia. Stress/adaptation and existentialism. The Gerontologist 37, 250-257.

Ganzeboom HBG and Treiman DJ (1996) Internationally comparable measures of occupational status for the 1988 International Standard Classification of Occupations. Social Science Research 25, 201-239.

Ganzeboom HBG, De Graaf PM and Treiman DJ (1992) A standard international socio-economic index of occupational status. Social Science Research 21, 1-56.

Gordon JR and Rouse ED (2013) The relationship of job and elder caregiving involvement to workcaregiving conflict and work costs. Research on Aging 35, 96-117.

Gordon JR, Pruchno RA, Wilson-Genderson M, Murphy WM and Rose M (2012) Balancing caregiving and work. Role conflict and role strain dynamics. Journal of Family Issues 33, 662-689.

Hank K and Stuck S (2008) Volunteer work, informal help, and care among the 50+ in Europe. Further evidence for 'linked' productive activities at older ages. Social Science Research 37, 1280-1291.

Henkens K, van Solinge H, Damman M and Dingemans E (2017) Design and Codebook of the NIDI Pension Panel Study (NPPS) First Wave, 2015. The Hague: NIDI.

Hill EJ, Grzywacz JG, Allen S, Blanchard VL, Matz-Costa C, Shulkin S and Pitt-Catsouphes M (2008) Defining and conceptualizing workplace flexibility. Community, Work \& Family 11, 149-163.

Hoffman GJ, Lee J and Mendez-Luck CA (2012) Health behaviors among Baby Boomer informal caregivers. The Gerontologist 52, 219-230.

Josten E and de Boer AH (2015) Concurrentie tussen mantelzorg en betaald werk [Competition Between Informal Care and Paid Work]. The Hague: Sociaal en Cultureel Planbureau.

Kim Y, Loscalzo MJ, Wellisch DK and Spillers RL (2006) Gender differences in caregiving stress among caregivers of cancer survivors. Psycho-Oncology 15, 1086-1092.

Kim J, Ingersoll-Dayton B and Kwak M (2013) Balancing eldercare and employment: the role of work interruptions and supportive employers. Journal of Applied Gerontology 32, 347-369.

Kramer BJ (1997a) Differential predictors of strain and gain among husbands caring for wives with dementia. The Gerontologist 37, 239-249.

Kramer BJ (1997b) Gain in the caregiving experience. Where are we? What next? The Gerontologist 37, 218-232.

Kruithof WJ, Post MWM and Visser-Meily JMA (2015) Measuring negative and positive caregiving experiences. A psychometric analysis of the Caregiver Strain Index expanded. Clinical Rehabilitation 29, 1224-1233.

Labra C de, Millan-Calenti JC, Bujan A, Nunez-Naveira L, Jensen AM, Peersen MC, Mojs E, Samborski W and Maseda A (2015) Predictors of caregiving satisfaction in informal caregivers of people with dementia. Archives of Gerontology and Geriatrics 60, 380-388.

Lawton MP, Kleban MH, Moss M, Rovine M and Glicksman A (1989) Measuring caregiving appraisal. Journal of Gerontology 44, 61-71.

Lawton MP, Moss M, Kleban MH, Glicksman A and Rovine M (1991) A two-factor model of caregiving appraisal and psychological well-being. Journal of Gerontology 46, 181-189.

Lilly MB, Laporte A and Coyte PC (2007) Labor market work and home care's unpaid caregivers. A systematic review of labor force participation rates, predictors of labor market withdrawal, and hours of work. Milbank Quarterly 85, 641-690.

Lin IF, Fee HR and Wu HS (2012) Negative and positive caregiving experiences. A closer look at the intersection of gender and relationship. Family Relations 61, 343-358.

Longacre ML, Valdmanis VG, Handorf EA and Fang CY (2017) Work impact and emotional stress among informal caregivers for older adults. Journals of Gerontology: Psychological Sciences and Social Sciences 72B, 522-531. 
Lyonette C and Yardley L (2003) The influence on carer wellbeing of motivations to care for older people and the relationship with the care recipient. Ageing \& Society 23, 487-506.

Mello JD, Macq J, van Durme T, Ces S, Spruytte N, van Audenhove C and Declercq A (2017) The determinants of informal caregivers' burden in the care of frail older persons. A dynamic and role-related perspective. Aging \& Mental Health 21, 838-843.

Nijboer C, Triemstra M, Tempelaar R, Sanderman R and van den Bos GA (1999) Determinants of caregiving experiences and mental health of partners of cancer patients. Cancer 86, 577-588.

Organisation for Economic Co-operation and Development (2015) Pensions at a Glance 2015: OECD and G20 Indicators. Paris: OECD Publishing.

Pavalko EK and Henderson KA (2006) Combining care work and paid work. Research on Aging 28, 359-374.

Pearlin LI, Mullan JT, Semple SJ and Skaff MM (1990) Caregiving and the stress process. An overview of concepts and their measures. The Gerontologist 30, 583-594.

Pinquart M and Sörensen S (2003) Associations of stressors and uplifts of caregiving with caregiver burden and depressive mood. A meta-analysis. Journals of Gerontology: Psychological Sciences and Social Sciences 58B, 112-128.

Plaisier I, Broese van Groenou M and Keuzenkamp S (2015) Combining work and informal care. The importance of caring organisations. Human Resource Management Journal 25, 267-280.

Pristavec T (2019) The burden and benefits of caregiving: a latent class analysis. The Gerontologist 59, 1078-1091.

Raschick M and Ingersoll-Dayton B (2004) The costs and rewards of caregiving among aging spouses and adult children. Family Relations 53, 317-325.

Schieman S, Whitestone YK and van Gundy K (2006) The nature of work and the stress of higher status. Journal of Health and Social Behavior 47, 242-257.

Statistics Netherlands (2019) Arbeidsdeelname; kernciffers. Available at http://statline.cbs.nl/statweb/.

Tolkacheva N, Broese van Groenou M, de Boer AH and van Tilburg T (2011) The impact of informal care-giving networks on adult children's care-giver burden. Ageing \& Society 31, 34-51.

van Solinge H and Henkens K (2017) Older workers' emotional reactions to rising retirement age. The case of the Netherlands. Work, Aging and Retirement 3, 273-283.

Verbakel E, Metzelthin SF and Kempen GIJM (2016) Caregiving to older adults: determinants of informal caregivers' subjective well-being and formal and informal support as alleviating conditions. Journals of Gerontology: Psychological Sciences and Social Sciences 73B, 1099-1111.

Verbeek-Oudijk D, Woittiez I, Eggink E and Putman L (2014) Who Cares in Europe? A Comparison of Long-term Care for the Over-50s in Sixteen European Countries. The Hague: Sociaal en Cultureel Planbureau.

Voydanoff P (2004) The effects of work demands and resources on work-to-family conflict and facilitation. Journal of Marriage and Family 66, 398-412.

Yates ME, Tennstedt S and Chang B-H (1999) Contributors to and mediators of psychological well-being for informal caregivers. Journals of Gerontology: Psychological Sciences and Social Sciences 54B, 12-22.

Zarit SH (2012) Positive aspects of caregiving. More than looking on the bright side. Aging \& Mental Health 16, 673-674.

Cite this article: Grünwald O, Damman M, Henkens K (2021). Providing informal care next to paid work: explaining care-giving gratification, burden and stress among older workers. Ageing \& Society 41, 2280-2298. https://doi.org/10.1017/S0144686X20000215 